\title{
Evaluation of stress parameters in new medical entrants based on their admission criteria to a south Indian medical college
}

\author{
Manju C. ${ }^{1}$, Alexander R. ${ }^{2 *}$, Divakaran B. ${ }^{3}$ \\ DOI: https://doi.org/10.17511/ijmrr.2019.i04.04 \\ 1 Manju C., Assistant Professor, Department of Physiology, Army College of Medical Sciences, , Delhi, India. \\ 2* Reena Alexander, Associate Professor, Department of Physiology, Sree Narayana Institute of Medical Sciences, Ernakulum, Kerala, India. \\ 3 Binoo Divakaran, Assistant Professor, Biostatistics, Department of Community Medicine, Academy of Medical Sciences, Kannur, Kerala, \\ India.
}

Objectives: Globally medical education is now recognized as a highly stressful course and students that enter this program are subject to multiple stress producing factors that affect their academic performance as well as their mental and physical well being. This study was done to determine the prevalence of stress among first year medical (MBBS) students based on their admission criteria and to identify the sources of stress among them. Material and method: A Cross sectional study. The study was conducted in a semi-government medical college, Kerala, India. Subjects included first year medical students (both male and female) enrolled in the college during the year of study. Interventions: GHQ-12 Questionnaire was used to assess the psychological stress. A pretested structured closed ended questionnaire to collect information regarding the academic and nonacademic sources of stress was charted out. Result: A total of 100 students were admitted to the first year of which 85 consented to take part in this study. Of the 85 students, $42(49.4 \%)$ were having stress. Of these, 35 (83.3\%) were repeaters (attempted the medical entrance examination more than once) and among them, 26 (61.9\%) were students who secured admission based on merit. A statistically significant association was seen between the number of attempts, admission criteria and stress $(p<0.05)$. Conclusions: This study found that stress was more among repeaters and those who secured admission based purely on merit. Nonresident Indian (NRI) students who secured admission through higher financial investments along with sudden displacement from home environment also suffered from significant stress levels. The possible sources of stress found in the study can be a preliminary step towards developing solutions for stress management and stress prevention in new medical entrants which could help in developing a new generation of stress free doctors capable of effectively providing high quality medical care to the community at large.

Keywords: Repeaters, Medical students, Stressors

Corresponding Author

Reena Alexander, Associate Professor, Department of Physiology, Sree Narayana Institute of Medical Sciences, Ernakulum, Kerala, India.

Email: drreenaalexander@gmail.com
How to Cite this Article

Manju C, Alexander R, Divakaran B. Evaluation of stress parameters in new medical entrants based on their admission criteria to a south Indian medical college. Int J Med Res Rev. 2019;7(4):273-279. Available From

https://ijmrr.medresearch.in/index.php/ijmrr/article/ view/1069
To Browse

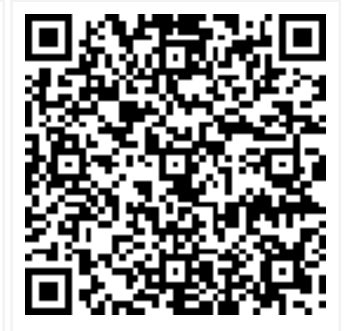

Manuscript Received 2019-06-10

Conflict of Interest No

Review Round 1
2019-06-20
Funding
Nil

(C) 2019 by Manju C., Reena Alexander, Binoo Divakaran and Published by Siddharth Health Research and Social Welfare Society. This is an Open Access article licensed under a Creative Commons Attribution 4.0 International License https://creativecommons.org/licenses/by/4.0/ unported [CC BY 4.0].

\author{
Review Round 2 \\ 2019-06-28 \\ Ethical Approval \\ Yes
}

Accepted 2019-07-03

Note 


\section{Introduction}

Since ancient times, medical profession in the Indian community has been a highly valued profession and medical practitioners were considered next to God as they were directly involved in serious life and limb-saving procedures. Apart from its holistic nature, the economic stability and social status that the profession lends, attracts the best of the academic scholars following their pre-degree course to this profession. Over the last few decades the selection process for admission to Indian medical schools has become highly competitive and complicated with lakhs of students applying for a few thousand seats on the basis of merit and multiple other socio economic parameters.

However in this process, the new medical entrants have been found to undergo a lot of stress which they find difficult to cope up with. Stress can be defined as an uncomfortable emotional experience that is accompanied by predictable biochemical, physiological and behavioral changes [1]. Various authors [2-5] have shown medical schools to be the most stressful with high incidences of depression, academic stress, sedative abuse, psychiatric illness and burnout among medical practitioners. It is inevitable that today's medical students will become tomorrow's medical practitioners and therefore finding solutions and relieving early medical practitioners from stress has become a very relevant issue in our society as they are the primary upholders of heath and preventers of sickness [6].

The present study was conducted with basic objective of identifying potential stress factors including both academic and non-academic factors among medical students and the early detection of stress could help us devise protocols to prevent the progression of unhealthy stress factors in young budding doctors.

\section{Materials \& Methods}

Place of study and type of study: This study was conducted at a semi-government medical college, Kerala, India. A cross-sectional survey was done using an anonymous self-administered questionnaire.

Sample methods: All hundred students who were (both male and female) enrolled in the first year were requested to participate in this survey at the end of their first academic year.
Prior approval was obtained from the ethics Committee of the Institution to undertake this study.

Sample collection: Students were briefed on the objective and purpose of the study and consenting participants were included in this study. The anonymity and confidentiality of the participants were assured during the study. General information of the participants such as age, sex, residence, locality (rural/urban) was collected. The questionnaire included the influence of various factors liable to cause stress such as: mode of admission to college (purely on merit/ reserved seats as management quota/ reserved seats for Non-resident Indian quota), fresher's (those who attempted the medical entrance examination for the first time)/ repeaters (those who attempted medical entrance examination more than once), medium of communication in school (local language/English), Current residence (day scholar/ hosteller) and parental interaction.

Evaluation of stress factors: The participants were provided with a 12-item General Health Questionnaire (GHQ-12) [7] and a list of 14 possible potential stress factors including both academic and non-academic issues. A scoring system was devised for different responses selected for each question with the total maximum possible score of 36 . The scoring given for the various responses were: Better than usual/not at all (0), same as usual (1), less than usual (2) and much less than usual (3). The possible academic and non-academic stress factors influencing the current student population were assessed based on a pretested structured closed ended questionnaire. Students with a general healthcare questionnaire score greater than 15 were considered stressed.

Inclusion criteria: all hundred students who were enrolled for the first year course were requested to take part in this study.

Exclusion criteria: only first year students were included, all other years were excluded. Also students who did not consent to take part were also excluded.

Statistical analysis: Statistical Analysis of the results was done using descriptive tools such as frequency and percentage. The significance of the study was assessed by $\mathrm{t}$ - test, chi-square test and Fisher's exact test and $\mathrm{p}$ value $<0.05$ was considered significant. 


\section{Results}

While a total of 100 medical students were admitted to the first academic year, only 85 took part in the study. Among the 85 students 62 (73\%) were females and 23 were males (27\%). Most of the students in the study belonged to the age group 19 years- $53(62.3 \%)$, along with $17(20 \%)$ students of age group 18 years and $15(17.6 \%)$ students being of age group 20 years.

A predominance of female candidates was observed with female: male ratio of $3: 1$. Majority of the students belonged to the urban population 53 $(62 \%)$ and almost $71(83.5 \%)$ of the students had gained medical admission as 'repeater' rather than as 'freshers'.

Irrespective of rural or urban origin, majority of the students in this study group had undergone their preliminary education in English medium schools. Students with a general healthcare questionnaire score greater than 15 were considered stressed.

Figure 1 depicts the number of students by age, sex, whether admitted through merit, management quota or NRI quota and 'repeaters' or 'freshers' category in a graphical format. It was noted that 78 $(91.7 \%)$ of the students in this study were hostellers compared to day scholars.
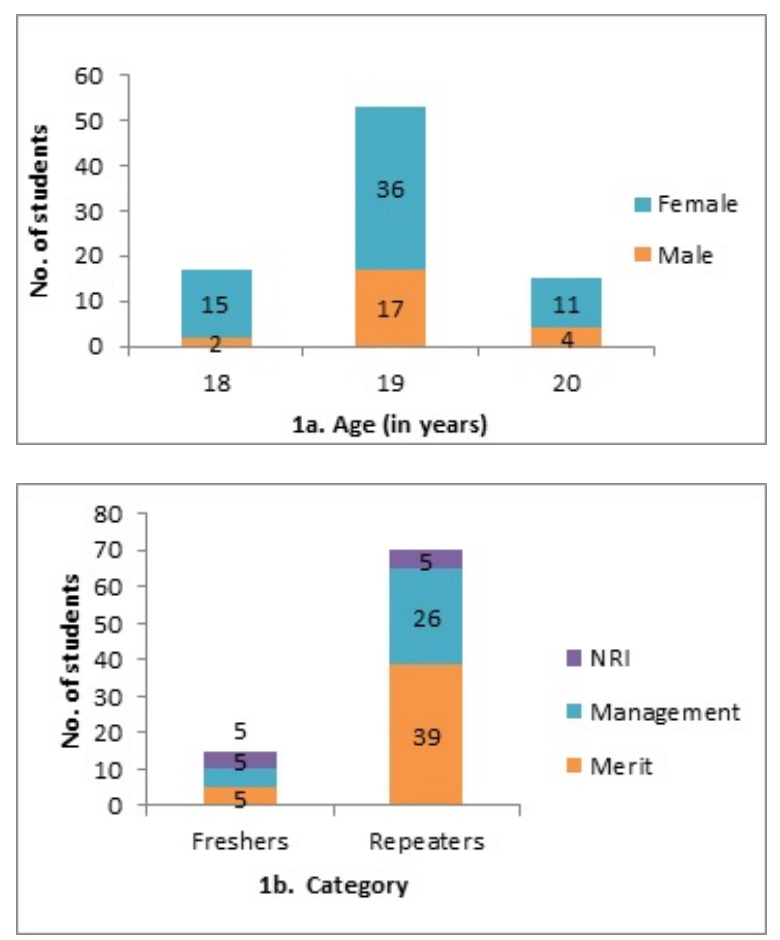

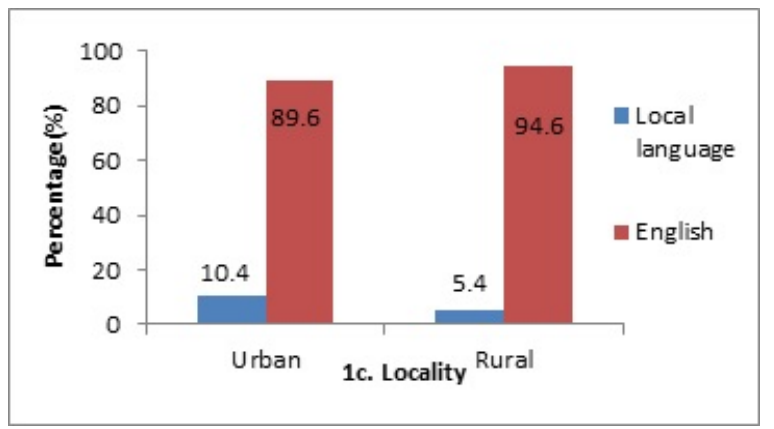

Fig-1: Description of various parameters describing the group of students in this study (a) Age \& sex distribution (b) Category based admission and whether 'freshers' or 'repeaters' (c) Rural or urban residence along with medium of instruction

The evaluation of various stress factors indicated that $43(50.6 \%)$ of the students were non-stressed, whereas $42(49.4 \%)$ of students were stressed. In the 'fresher's group, NRI students were found to be the most stressed, while in the 'repeaters' group, the merit students were the most stressed (Figure 2).

A close examination of various academic sources of stress revealed that multiple factors such as heavy workload, long working hours, frequent examinations, competition for success, teaching language and amount of syllabus accounted for more than $50 \%$ the stress recorded in the students (Figure 3).

Among the nonacademic factors contributing to stress, parental pressure and lack or recreation time accounted for $83.3 \%$ and $81.5 \%$ of stress causes, followed by homesickness (65.6\%) and lack of time management at $58.8 \%$.

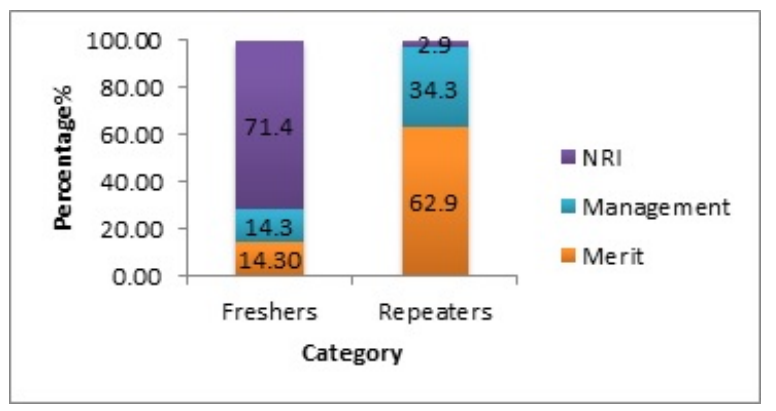

Fig-2: Prevalence of stress in medical students based on their mode of entry to college 

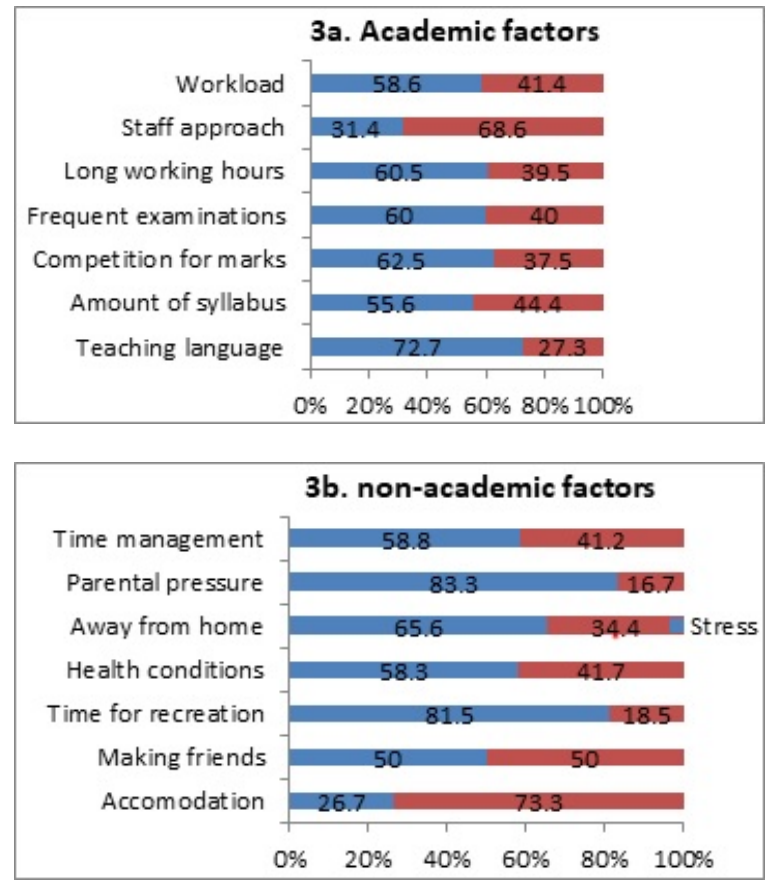

Fig 3a \& b. Graphical depiction of various academic and non-academic stress factors among the students population

\section{Discussion}

As societies evolve over time the realization that higher learning and superior skills will bring better futures has encouraged young people from diverse backgrounds to participate in higher education and arts- something their ancestors would never have dreamt off. The need to study and excel academically can become problematic when it reaches a point where it begins to interfere with social functioning, recreation, personal health, family relationships and happiness. It should be noted that mild stress tends to motivate the students, while severe stress can lead to psychological and physical ill health.

The selection of a semi governmental medical college in this study presented an advantage by getting a wide type of students including nonresident Indians, management quota and merit based students. The present study showed that 42 $(49.4 \%)$ of students were under stress and $43(50.6$ $\%)$ of the students were not stressed. Among the eighty five students 62 were females and 23 were male students. Female students were found to be more stressed than their male counterparts and this finding was similar to the study done by Gade $\mathrm{S}$ et al [8].
NRI students were more stressed in the 'fresher's group while merit students were more stressed among the 'repeaters' category (Figure 2).

This variation could be due to the high burden of parental expectations and fulfillments bestowed on fresher NRI students and meritorious repeater students. An additional factor that could account for this increased stress among NRI students could be the high fees paid by their parents for admission. Unlike other reports the current study covered a variety of students from different backgrounds, which probably accounted for the presence of equally stressed and non-stressed individuals. In a study done in Iraq, the highest population of students with stress were first year students $(11.5 \%)$ when compared to other senior students and similar to the present study, stress was more in female students as compared to males [1].

Medium of communication also contributed to stress among students although most of them had their schooling in English language and this could be attributed to the exposure to medical terms for the first time.

Long working hours, frequent examinations, vast syllabus and heavy work load were the other major academic stressors. Among the non- academic stressors, parental pressure was a major factor for stress among students. Less time for recreation, poor time management and being away from home and adjustment problem to new surroundings also contributed to stress among medical students. Many studies done in this field have also identified stressors similar to the present study. Studies by Waqas et al [3] showed academic stressors contributed significantly to stress and sleep disorders in medical students.

Sherina et al [2] reported that psychological stress in medical students was associated with depression. A study among Norwegian medical students by Tyssen et al [9] found that suicidal tendencies in medical school was significantly predicted by mental distress and depression'. Individual Personality plays a big role in stress and while Personality traits may modify the perception of and responses to stress, high levels of conscientiousness and neuroticism was shown to be associated with higher stress levels during medical studies [10].

This study was comparable to a similar study done in Pakistan where $57.7 \%$ student subjects had moderate to extremely severe stress where in addition to common factors seen in the present 
Study, the pressure of living up to family's expectations, fear of stepping into the real world of medicine, taboo concerning mental health and dissatisfaction with the administration were also highlighted [11].

Similar to 'Workaholic 'people, it might be assumed that 'study obsessed' students may develop increased stress and inability to relax leading to anxiety, depression and other psychiatric issues [12]. An elevated study effort if unrewarded with higher grades could trigger consistent negative emotions and stress responses leading to mental ill health. A number of stress busting techniques have been suggested to reduce stress in students pursuing higher education.

Mindfulness, a secular face- to- face, group based skills training program that involves self-discovery, self-compassion, and empowerment, aimed at generating a natural transfer of skills developed in meditation to study, decision making and relationships, is one such means of training which has become acceptable to students and popular in universities.

Mindfulness has been recommended by the general medical council, UK as it has been shown to enhance resilience to stress and improve mental health [13, 14]. Other authors have suggested a yoga-inspired bio-psychosocial-spiritual model of self-care and execute life coaching to reduce stress in graduate healthcare students $[15,16]$. According to the happy-productive student theory student satisfaction depends on psychosocial factors such as coping, stress and well-being and must be able to identify and manage the causes of dissatisfaction among students in order to improve their psychological state and reduce stress levels [17].

Non academic stressors can be relieved by adequate recreational, refreshment facilities \& improving mess facilities. While digital addiction has now been recognized by $\mathrm{WHO}$ as a disease and needs to be tackled as well. Time management workshops are very important as most of the students spend a lot of time on their mobile phone. Ogba FN et al suggested that music therapy with relaxation technique was consistent at follow up in improving student stress management [18].

The 'Mentoring system' which helps to individually monitor students mental and physical well being could be given more importance and should be better developed.
In this system student oriented faculty members are selected and allotted about ten students each. Mentors and students meet once weekly and discuss all aspects relating their mental, physical and scholastic well being.

Based on these interactions, specific problems are identified and solutions suggested. Mentoring system should have close association with counseling cells, Psychiatrists, medical specialists, parents and anti ragging committee. In addition they should advice mindfulness workshops, yoga sessions, music club etc. which will improve the quality of student's life in the campus. This study has a few limitations as it did not focus on mental illnesses like depression and anxiety. Besides it is a single centre study and large scale multicentre studies will be needed to get a bigger and clearer picture of stress in medical students in the Indian background.

\section{Conclusion}

The journey through medical school can be a stressful experience for new entrant students, resulting in stress-related mental health issues which appear to be seriously under diagnosed in the back ground of Indian medical education. This study found that stress was more among repeaters and those who had secured admission based on merit. The possible sources of stress found in the study can be a preliminary step towards developing solutions for stress management in medical students. Stress among students can be reduced by modifying the curriculum and by adding more time for recreation and sports. Mentoring system where trained mentors persistently interact with students to see their psychological and physical well being, while continuing a healthy academic could be given more importance and be developed and integrated into all medical courses. The present study deserves a follow-up to reach its assigned purpose, in particular by widening the sample size and by extending the research to other university students.

\section{What does the present study add to the existing knowledge?}

The present study gives a better insight into the stress factors that affect present day medical aspirants who are exposed to a multitude of admission criterion which they have no control off, but are forced to accept if they are to continue with their medical career. 
A thorough understanding of these factors will help these students tackle stress and as doctors provide better service to the community at large.

\section{Author's contribution}

The first and second authors were involved in collection of data, its analysis, review of literature and writing up the paper.

The third author was involved in the data organization and statistical analysis.

\section{Reference}

01. Shawi AFA, Abdullateef AN, Khedher MA, Rejab MS, Khaleel RN. Assessing stress among medical students in Anbar governorate, Iraq- a cross-sectional study. Pan Afr Med J. $2018 ; 31 ; 96$.

DOI: 10.11604/pamj.2018.31.96.16737 [Crossref]

02. Sherina MS, Rampal L, Kaneson N. Psychological stress among undergraduate medical students. Med J Malaysia. 2004;59(2)207-11.

[Crossref]

03. Waqas A, Khan S, Sharif W, Khalid U, Ali A. Association of academic stress with sleeping difficulties in medical students of a Pakistani medical school- a cross sectional survey. Peer J. 2015; $12 ; 3 ; \mathrm{e} 840$.

DOI: $10.7717 /$ peerj. 840 [Crossref]

04. Ko SM, Kua EH, Fones CS. Stress and the undergraduates. Singapore Med J. 1999;40(10)62730.

[Crossref]

05. Saipanish R. Stress among medical students in a Thai medical school. Med Teach. 2003;25(5)502-6.

DOI: $10.1080 / 0142159031000136716$ [Crossref]

06. Shapiro SL, Shapiro DE, Schwartz GE. Stress management in medical education- a review of the literature. Acad Med. 2000;75(7)748-59.

[Crossref]

07. Goldberg DP, Blackwell B. Psychiatric illness in general practice- a detailed study using a new method of case identification. $\mathrm{Br}$ med $\mathrm{J}$. $1970 ; 2(5707) 439-43$.

DOI: $10.1136 / \mathrm{bmj} .2 .5707 .439$ [Crossref]
08. Gade S, Chari S, Gupta M. Perceived stress amo ng medical students- To identify its sources and coping strategies. Arch Med Health Sci. 2014;2 (1)80-6. DOI: $10.4103 / 2321-4848.133845$ [Crossref]

09. Tyssen R, Vaglum P, Grønvold NT, Ekeberg O. Suicidal ideation among medical students and young physicians- a nationwide and prospective study of prevalence and predictors. J Affect Disord. 2001;64(1)69-79.

DOI: $10.1016 /$ S0165-0327(00)00205-6 [Crossref]

10. Bergmann C, Muth T, Loerbroks A. Medical students' perceptions of stress due to academic studies and its interrelationships with other domains of life- a qualitative study. Med Educ Online. $2019 ; 24(1) 1603526$.

DOI: $10.1080 / 10872981.2019 .1603526$ [Crossref]

11. Kumar B, Shah MAA, Kumari R, Kumar A, Kumar J, Tahir A. Depression, Anxiety, and Stress Amo ng Final-year Medical Students. Cureus. 2019;11(3)e4257.

DOI: $10.7759 /$ cureus.4257 [Crossref]

12. Marazziti D, Presta S, Baroni S, Silvestri S, Dell' Osso L. Behavioral addictions- a novel challenge for psychopharmacology. CNS Spectr. 2014;19

(6)486-95. DOI: 10.1017/S1092852913001041 [Crossref]

13. Galante J, Dufour G, Vainre $M$, Wagner AP, Stochl J, Benton A, et al. A mindfulness-based intervention to increase resilience to stress in university students (the Mindful Student Study)a pragmatic randomised controlled trial. Lancet Public Health. 2018;3(2)e72-e81.

DOI: $10.1016 / \mathrm{S} 2468-2667(17) 30231-1 \quad$ [Crossref]

14. Malpass A, Binnie K, Robson L. Medical Students' Experience of Mindfulness Training in the UK- Well-Being, Coping Reserve, and Professional Development. Educ Res Int. 2019.

DOI: 10.1155/2019/4021729 [Crossref]

15. Klawonn A, Kernan D, Lynskey J. A 5-Week Seminar on the Biopsychosocial-Spiritual Model of Self-Care Improves Anxiety, Self-Compassion, Mind-fulness, Depression, and Stress in Graduate Healthcare Students. Int J Yoga Therap. 2019 May 30.

DOI: $\quad 10.17761 / \mathrm{D}-18-2019-00026$ [Crossref] 
16. Cameron D, Dromerick LJ, Ahn J, Dromerick AW. Executive/life coaching for first year medical students- a prospective study. BMC Med Educ. $2019 ; 19(1) 163$.

DOI: $\quad 10.1186 / s 12909-019-1564-4 \quad$ [Crossref]

17. Cotton S, Dollard $M$, De Jonge J. Stress and student job design- Satisfaction, well-being, and performance in university students. International Journal of Stress Management. 2002;9(3)147-162.

[Crossref]
18. Ogba FN, Ede MO, Onyishi CN, Agu PU, Ikechukwu-Ilomuanya $A B$, Igbo $J N$ et al. Effectiveness of music therapy with relaxation technique on stress management as measured by perceived stress scale. Medicine (Baltimore). 2019;98(15)e15107.

DOI: 10.1097/MD.0000000000015107 [Crossref] 